\title{
New Extended Quantitative Local and Global Regularity Index for Single- and Multiframe RC Bridges Based on Modal Vector Correlation
}

\author{
Elham Aboutorabian (iD and Morteza Raissi Dehkordi \\ School of Civil Engineering, Iran University of Science and Technology, Tehran, Iran \\ Correspondence should be addressed to Morteza Raissi Dehkordi; mraissi@iust.ac.ir
}

Received 26 April 2021; Revised 7 June 2021; Accepted 18 June 2021; Published 28 June 2021

Academic Editor: Angelo Marcelo Tusset

Copyright (c) 2021 Elham Aboutorabian and Morteza Raissi Dehkordi. This is an open access article distributed under the Creative Commons Attribution License, which permits unrestricted use, distribution, and reproduction in any medium, provided the original work is properly cited.

\begin{abstract}
Seismic demand and performance of bridges are highly dependent upon the level of irregularity. Although previous studies have proposed methodologies so as to quantify the irregularity of the bridges in terms of global regularity index, it still remains unclear how to determine the distribution of irregularity along a bridge, as well as to discover the irregularity sources. This research project is intended to develop a quantitative vector regularity criterion for single- and multiframe bridges based on the modified correlation function for spatial locations of scaled mode shapes of deck-alone and whole bridge. The proposed criterion calculates two types of regularity indices, namely, local (LRI) and global regularity indices (GRI). The GRI is a scalar value representing the overall regularity of the entire bridge, whereas the LRI highlights vector irregularity distribution along the bridge. Since the deck discontinuity due to the in-span hinges is one of the leading causes for irregularity, the proposed index has been employed in case of multiframe bridges as well. Furthermore, the current study aims to investigate the correlation between the proposed irregularity indicators and the nonlinear to linear demand ratio. Therefore, the appropriate analysis method can be chosen based on irregularity extent of bridges. Obtained results of the proposed indices reveal that in-span hinge is one of the main parameters affecting the distribution of local irregularity along a bridge. Therefore, multiframe bridges need to be investigated in detail so as to validate the special design requirements recommended by design codes.
\end{abstract}

\section{Introduction}

In regard to past earthquakes, it is observed that, during severe earthquakes, seismic damage is highly dependent upon the level of bridge irregularity [1-3]. Regularity of bridges has been defined in various ways. According to the AASHTO, the irregularity depends on geometric properties of bridges such as the number of spans, adjacent spans length ratio, subtended angle for curved bridges, and span-to-span piers stiffness ratio [4]. As the first attempt to provide a measure of the bridge regularity, an index is suggested by Calvi comparing the behavior of the deck and whole bridge in the linear phase using the orthogonality property of the eigenvectors [5]. Ewins provides different definitions for regularity index using Modal Assurance Criterion (MAC) as well as Modal Scale
Factor (MSF) which are well recognized in model updating or modal correlation of structural responses [6]. Akbari and Maalek proposed a regularity index based on the differences between the seismic responses of the intended and reference bridges. This index is calculated using the simplified elastic UL, SM, or MM analysis methods as presented in AASHTO specifications [7]. A criterion of structural regularity for reinforced concrete multispan bridges was proposed by Grendene et al. which is based on equivalent single degree-of-freedom system [8]. They concluded that when the deck is stiff enough to control pier displacements, and the distribution of pier's stiffness is symmetric, the proposed criterion offers reasonable accuracy. Several studies served the relative stiffness of deck to piers as an indicator of bridge irregularity $[9,10]$. Akbari and Maalek carried out an 
exhaustive comparison between different regularity indices [11]. The effects of the combinations of various irregularity types on seismic ductility of bridges were investigated by Sajed and Tehrani [12]. As mentioned above, all existing regularity indices represent the regularity by merely an individual parameter which is a representative of overall bridge regularity (global regularity). Meanwhile, regarding geometric and mechanical specifications of a bridge, different parts of it could be associated with different levels of regularity (local regularity). Therefore, this study deals with identifying the sources of irregularity by introducing a localized regularity index.

Another factor dramatically affecting the irregularity in bridges is the existence and location of the in-span hinges, which is ignored in previous studies. Past earthquakes have confirmed that multiframe bridges, due to the complexities of their discrete system, are more vulnerable to the earthquake induced failure compared to regular ones [13]. Several studies surveyed the effect of in-span hinges on the seismic response of multiframe bridges $[14,15]$. Due to the fact that most of the research efforts regarding in-span hinges have focused on the seismic behavior of multiframe bridges, therefore, this has led to lack of comprehensive investigation on the effects of in-span hinges on regularity index.

Based on the seismic design codes, structural regularity is of paramount importance and needs to be taken into account during the setup of the analysis method for a complex system [4]. In the cases of high irregularity, the system's deformed shape predicted by linear analysis can be very different from actual deformation during a seismic event [16]. Ayala and Escamilla investigated the modal irregularity index and the effect of this characteristic on the seismic performance of bridges using simplified methods of analysis [17]. Li et al. proposed a new nonlinear static procedure to estimate the elastoplastic displacement demand for symmetrical irregular bridges [18]. Unfortunately, despite several research projects in the course of past decade, the choice of suitable analysis method based on the irregularity level of bridges, especially in the cases of multiframe ones, has not been addressed.

In this paper, due to the lack of criterion for local irregularity, a quantitative vector regularity index for singleand multiframe bridges is proposed to detect the sources of irregularity along the bridge length through local RI. The new index is generated based on the refined equations in terms of modal vector correlation of deck-alone and whole bridge. The index proposes two new parameters so as to characterize bridge regularity as local (LRI) and global (GRI) regularity criterion to yield valid evaluation results. It is shown that the GRI and LRI could be used for a variety of purposes, including detecting sources of irregularity, determining regularity of each node along bridge, choosing the appropriate analysis method, and positioning the in-span hinges, as well as estimating the nonlinear to linear demand ratio at different parts of a bridge. In addition, this study reveals that local and global regularity are in close correlation with the maximum nonlinear to linear displacement ratio in the cases of single- and multiframe bridges.

\section{Proposed Regularity Index Formulation}

Up to now, the notion of local regularity along the bridge length has not been presented. The formulation proposed in this section aims to develop a novel vector criterion representing regularity level in each node along the bridge; hence, the contribution of each node in overall irregularity and sources of irregularity would be revealed. The proposed method, referred to as GRI and LRI here, uses and refines the concept of correlation function for spatial locations of scaled mode shapes (COMEF) in the field of experimental vibration analysis proposed by Catbas and Aktan [19]. The new method modifies summation vector using square root of sum of squares (SRSS). Afterwards, inspired by error function in COMEF formulation, the local and global regularity indices are developed. Summation vector and error function will be introduced in the following section. The refined method employs a series of scaling factors to minimize the contribution of low-amplitude nodes. The proposed index is based on the correlation of two sets of modal vectors, related to entire bridge and deck alone, having the same number of nodes $(n)$ and matching modes $(m)$. The procedure to calculate the proposed regularity index is the following steps.

Firstly, mode shapes are normalized to modal mass (as (1)), in order to make them comparable.

$$
\begin{aligned}
\widetilde{\varnothing_{i A}} & =\frac{\varnothing_{i A}}{\sqrt{m_{i A}}}, \\
\widetilde{\varnothing_{i B}} & =\frac{\varnothing_{i B}}{\sqrt{m_{i B}}}, \\
\varnothing_{i}^{T}[M] \varnothing_{i} & =m_{i},
\end{aligned}
$$

where,

$\varphi_{i}^{A}$ is the $i^{\text {th }}$ normalized eigenvector of the deck with the stiffness of piers included

$\varphi_{i}^{B}$ is the $i^{\text {th }}$ normalized eigenvector of the deck-alone without the stiffness of piers included

$M$ is the mass matrix of the deck

The second step is to calculate the error matrix for all intended paired modes at each node as shown in

$$
[\mathrm{ERI}]=\widetilde{\varnothing_{B}}-\widetilde{\varnothing_{A}},
$$

where [ERI] is the error matrix representing the difference between two modal vector sets of an $n \times m$ matrix. In the error matrix, one finds cases in which certain nodes present high error values. It should be noted that the $i^{\text {th }}$ mode of the deck-alone is paired with the $i^{\text {th }}$ mode of the whole bridge. It is not difficult to distinguish the paired modes in lower modes but might be ambiguous in the case of higher modes. It is recommended to use modal assurance criterion (MAC) to accurately pair the modal shapes of the entire bridge and deck-alone [6]. That way, the irrelevant mode shapes are eliminated.

Since different nodes contribute in irregularity with different shares, a further step is then needed so as to determine the weighting matrix. By using the weighting 
matrix, the effects of low-amplitude nodes are weighted with smaller factors and vice versa. In order to generate the weighting matrix, the modified summation vectors are used. The refined summation vector $\left(\mathrm{SV}_{i}\right)$ is a combination of mode shape coefficients of each node $i$ over all the modes that are included in the analysis. The square root of the sum of the squares (SRSS) over all intended modes is used to determine the $\mathrm{SV}_{i}$, which is an individual value for each node.

$$
\mathrm{SV}_{i}=\sqrt{\sum_{j=1}^{m} \varnothing_{B i j}^{2}}, \text { for } i=1, \ldots, n
$$

By multiplying the spatial location, i.e., modal shape of the deck alone $\left(\varnothing_{B}\right)$, and the corresponding element from the summation vector $\left(\mathrm{SV}_{i}\right)$, the weighting matrix $(\mathrm{WM})$ can be expressed as follows:

$$
\mathrm{WM}_{i j}=\varnothing_{B i j} \times \mathrm{SV}_{i} .
$$

After the weighting matrix is obtained, the error values are weighted and combined over all the considered modes, and refined coordinate modal error function $\left(\psi_{i}\right)$ is calculated for each node.

$$
\psi_{i}=\frac{\sum_{j=1}^{m}\left(\mathrm{WM}_{i j} \times \mathrm{ERI}_{i j}\right)^{2}}{m}, \text { for } i=1, \ldots, n .
$$

The coordinate modal error function illustrates the irregularity of different nodes of the bridge. Finally, inspired by the concept of error function, the local regularity index for each node is achieved by unity minus the irregularity of the intended node. This parameter is denoted as local regularity index (LRI). Combining the LRI values along the bridge leads to an individual regularity value for the entire bridge, called the global regularity index (GRI).

Based on the abovementioned explanations, local and global regularity indices are calculated as follows:

$$
\begin{aligned}
\mathrm{LRI}_{i} & =1-\sqrt{\frac{\sum_{j=1}^{m}\left(\mathrm{WM}_{i j} \times \mathrm{ERI}_{i j}\right)^{2}}{m}}, \text { for } i=1, \ldots, n, \\
\mathrm{GRI} & =\sqrt{\frac{\sum_{i=1}^{m} \mathrm{LRI}_{i}^{2}}{n}} .
\end{aligned}
$$

The LRI and GRI are set up based on the correlation between the modal shape of the entire bridge and deck alone. Consequently, modal shapes are considerably affecting the RI results. The RI and GRI values range from zero to one. Similar to other regularity indices, where a value is closer to one, it shows a higher correlation agreement between deckalone and whole bridge, i.e., high level of regularity. The less this value becomes, the worse the eigenvector correlation will be, i.e., low regularity level. The nodes with LRI close to unity are the regular ones, while low-LRI nodes could be considered as sources of irregularity. In what follows, the proposed RI is calculated for eighteen types of altitudinal irregular single- and multiframe concrete box-girder bridges with low to high regularity index values.

\section{Bridge Specifications}

To investigate the dependency between irregularity and the analysis method and to validate the proposed local regularity index, the examples of viaduct-like reinforced concrete bridges are considered. For this purpose, to cover a wide range of irregularity and consider various positions of inspan hinges, three classes of four- and five-span bridges in the format of eighteen bridge types are utilized. Typical details for bridge models are adopted from a reliable research previously done [20]. The basic bridge model has been utilized as the reference model in several research projects and was served as prototype in European research program [11]. The bridge models consist of four and five $50 \mathrm{~m}$ spans and pier heights of $h=7 \mathrm{~m}, 14 \mathrm{~m}$, and $21 \mathrm{~m}$, with box section. The superstructure in all models has the same geometric and mechanical characteristics. The typical deck for models is $14 \mathrm{~m}$ wide with a continuous hollow box section. The piers consist of a single hollow rectangular column with uniform cross section. The geometric properties of the bridges are presented in Figure 1.3D nonlinear finite element models are generated. In order to cover a wide range of adjacent frames fundamental period ratio and irregularity, three classes of bridges are considered as follows.

3.1. Bridge Models of Type A. Three continuous four-span bridges with and without in-span hinges and various column heights are considered. Column heights include three values of 7, 14, and 21 meters. Model A111 is a bridge with three piers of equal height (a regular bridge), whereas model A131 has the highest irregularity with a more pronounced difference between the central and lateral pier heights (a highly irregular bridge). The geometric properties and location of hinges for bridge type A are depicted in Figure 2 and Table 1.

3.2. Bridge Models of Type B. The second group of models is composed of three continuous five-span bridges with and without in-span hinges. Figure 3 represents the bridge configuration. As is illustrated, the pier height symmetrically increases from side abutments to middle pier. Table 2 displays the model specifications and hinge location in each model of type B. All models are considered single- and multiframes.

3.3. Bridge Models of Type C. Figure 4 illustrates the longitudinal view of the bridges type $\mathrm{C}$. These models are fivespan continuous bridges with and without two in-span hinges. Therefore, three classes of multiframe bridges with a wide range of irregularity level and hinge location are considered. Table 3 depicts the model specifications and hinge locations in each model of type C.

\section{Numerical Modeling}

The OpenSees, an open-source finite element platform, was employed for 3D numerical modeling of bridges [21]. General configuration of models was adopted from those of Pinto [20]. Structural seismic design of considered bridges 


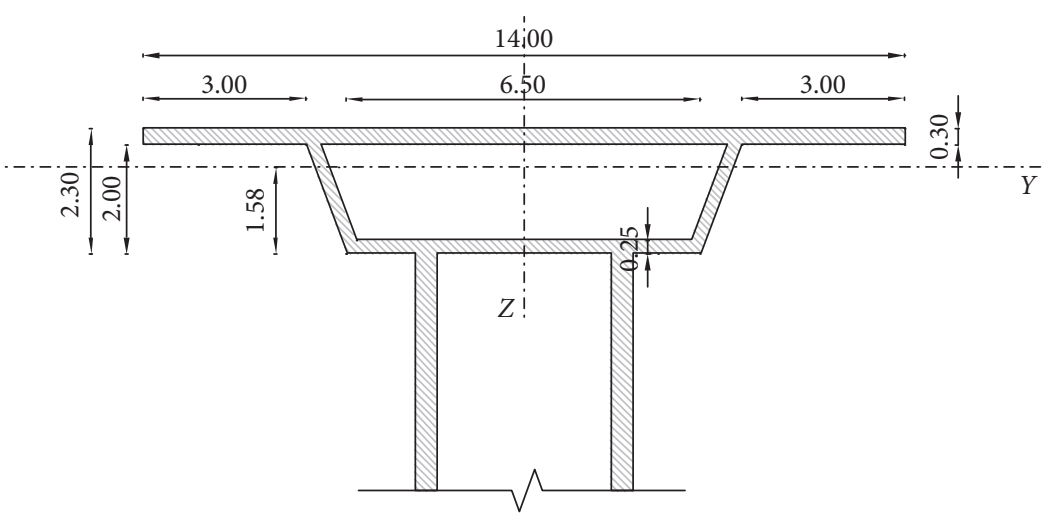

(a)

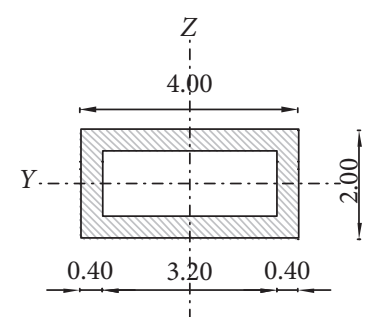

(b)

Figure 1: (a) Intended deck sections (m). (b) Cross section of columns (m).

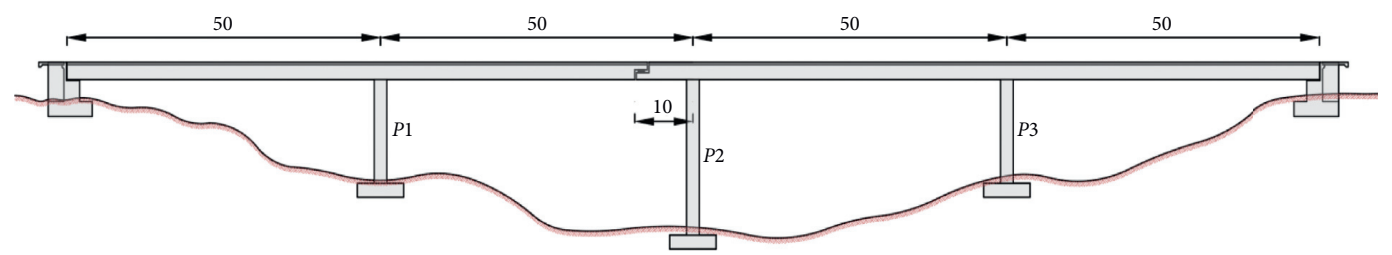

Figure 2: Bridge models: type A.

TABle 1: Bridge models: type A.

\begin{tabular}{lcccc}
\hline \multirow{2}{*}{ Bridge ID } & & Height $(\mathrm{m})$ & $P_{3}$ & Hinge location \\
& $P_{1}$ & $P_{2}$ & 7 & Span 2-10 m before $P_{2}$ \\
A111 & 7 & 7 & 7 & Span 2-10 m before $P_{2}$ \\
A121 & 7 & 14 & 7 & Span 2-10 m before $P_{2}$ \\
A131 & 7 & 21 & & 7 \\
\hline
\end{tabular}

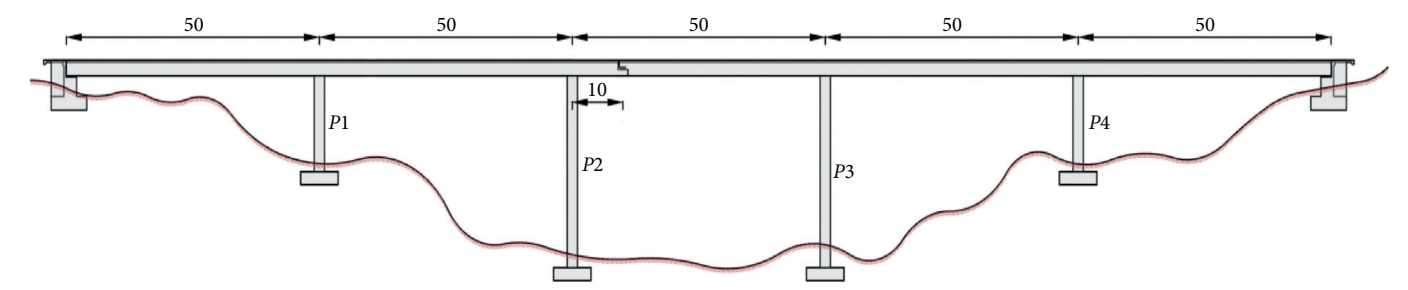

FIgURe 3: Bridge models: type B.

TABLe 2: Bridge models: type B.

\begin{tabular}{lccccc}
\hline \multirow{2}{*}{ Bridge ID } & \multicolumn{2}{c}{ Height $(\mathrm{m})$} & $P_{4}$ & Hinge location \\
& $P_{1}$ & $P_{2}$ & $P_{3}$ & 7 & Span 3-10 m after $P_{2}$ \\
B1111 & 7 & 7 & 7 & 7 & Span 3-10 m after $P_{2}$ \\
B1221 & 7 & 14 & 14 & 7 & Span 3-10 m after $P_{2}$ \\
B1331 & 7 & 21 & 21 & 7 & \\
\hline
\end{tabular}

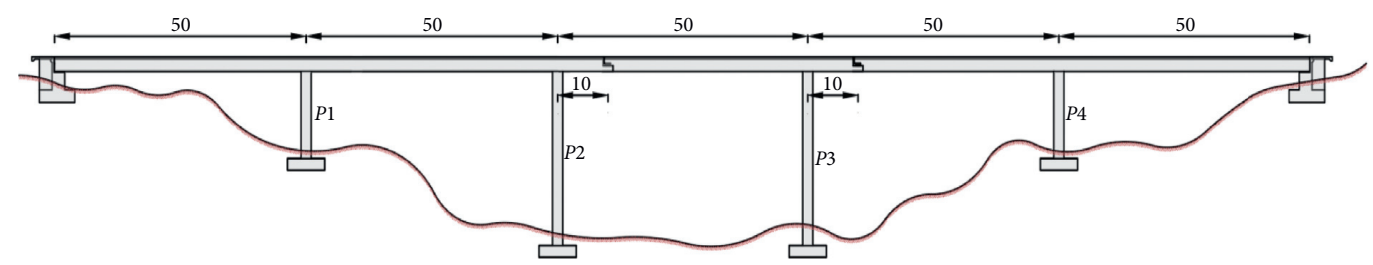

Figure 4: Bridge models: type C. 
TABle 3: Bridge models: type C.

\begin{tabular}{lccccccc}
\hline Bridge & \multicolumn{4}{c}{ Height $(\mathrm{m})$} & \multicolumn{2}{c}{ Hinge location } \\
ID & $P_{1}$ & $P_{2}$ & $P_{3}$ & $P_{4}$ & Hinge 1 & Hinge 2 \\
\hline C1111 & 7 & 7 & 7 & 7 & $\begin{array}{c}\text { Span 2-10 m } \\
\text { before } P_{2}\end{array}$ & Span 4-10 m after \\
& & & & & $\begin{array}{c}\text { Span 2-10 m } \\
\text { before } P_{2}\end{array}$ & $\begin{array}{c}\text { Span } 4-10 \mathrm{~m} \text { after } \\
P_{3}\end{array}$ \\
C1221 & 7 & 14 & 14 & 7 & $\begin{array}{c}\text { Span 2-10 m } \\
\text { before } P_{2}\end{array}$ & $\begin{array}{c}\text { Span 4-10 m after } \\
P_{3}\end{array}$ \\
C1331 & 7 & 21 & 21 & 7 & &
\end{tabular}

has been performed according to the Eurocode 8 design spectrum. The bridges were designed for the worst-case condition of static and dynamic load combinations in both longitudinal and transverse directions. In order to reflect the ductility capacity of the bridges, the behavior factor, $q$, of 2.5 was used with respect to the structural system of the bridges. Contribution of live load in seismic load was not required based on part 4.1.2 of EN 1998-2. The cross-sectional area of longitudinal reinforcement of piers is considered to be $2 \%$ of the gross cross-sectional area of the column. The volumetric ratio of the transverse reinforcement of piers has been assumed to be $0.5 \%$. Columns were modeled using the "nonlinear beam-column" element with fiber-defined cross section. The superstructure elements are expected to remain elastic and therefore are modeled using linear "elastic beamcolumn" elements with lumped mass at the top of each pier point. The bridge deck is overlaid with a $10 \mathrm{~cm}$ asphalt pavement. The structural weight and mass were calculated directly based on material density and volume, and specific weight of concrete and asphalt assumed to be 25 and $20 \mathrm{KN} /$ $\mathrm{m}^{3}$, respectively. The P- $\Delta$ effect was taken into account through the linear geometric transformation of beam stiffness and resisting force. A 5\% Rayleigh damping associated with the periods of 0.5 and $2.0 \mathrm{sec}$ is implemented to ensure similar damping values over a wide range of periods of vibration [22].

In this study, the uniaxial material "Concrete04" is used for modeling the reinforced concrete. This material serves Chang and Mander model to define the monotonic stressstrain relationships for confined concrete properties [23]. The compressive strength of $25 \mathrm{MPa}$ is considered for unconfined concrete. For reinforcing steel, the uniaxial "reinforcing steel" material with a $400 \mathrm{MPa}$ yield strength is utilized, which is developed from the base model proposed by Chang and Mander [24]. The deck to columns connections are considered to be monolithic and modeled using the rigid link.

In-span hinges are affected by concentrated bearing loads, access holes, and possible utilities. Therefore, they are disturbed regions with three-dimensional behavior and special considerations are required [25]. Abutments and inspan hinges are assumed to be equipped with shear keys. Hence, pin support is used in the transverse direction at the abutments. An assembly of "ZeroLength" elements is used to model the in-span hinges and abutments components. The abutment modeling in both longitudinal and transverse directions is implemented based on a model developed by Macki and Stojadinovic [26]. Longitudinal behavior of abutment is a function of subparts, including abutment backwall, elastomeric bearing, and gap, as well as backfill behind the abutment [26]. As long as the expansion joint is sufficiently large to accommodate the cyclic movement between the abutment wall and superstructure, the bearings are part of the earthquake resisting system (ERS). After the gap closure or impact events, a transfer of forces will occur from the superstructure to the abutment wall. As a result, the earth-pressure condition approaches full passive pressure. Similarly, there are several factors involved in the transverse response of the abutment including elastomeric bearing pads, shear keys, wing walls, and backfill material. The mathematical models of in-span hinge and abutments are shown in Figure 5. Shear keys are used to provide transverse restraint for bridge superstructures under seismic and nonseismic loads. The shear key capacity at in-span hinges is recommended to be the same as those of the closest pier [27]. The abutment shear keys capacity was assumed to be equal to the dead load reaction at the abutment [27]. A series combination of uniaxial "Steel02" material and "ImpactMaterial" was used for modeling this behavior. The "ImpactMaterial" in OpenSees is based on an approximation to the Hertz contact model proposed by Muthukumar [28]. Mentioned material was served for modeling the impact phenomenon and pounding effect on the shear keys, backwalls, and in-span hinges. The uniaxial "elastic" material is used to model the steel-reinforced elastomeric bearings in both horizontal and vertical directions. AASHTO [29] and Caltrans [27] consider a bilinear approximation of the forcedeformation relationship for passive soil pressure behind the abutments, while Shamsabadi et al. recommended the multilinear backbone curve [30]. The passive resistance of backfill soil was modeled using "hyperbolic gap material" proposed by Shamsabadi et al. [30]. The wing wall height was considered to be $1 / 3$ of the backwall height [31]. Mechanical and geometrical specifications of the studied bridges are listed in Table 4.

The soil beneath and around the column foundation was modeled by using the longitudinal, lateral, and rotational springs. The springs were modeled using linear material assigned to zero-length elements.

To validate the OpenSees models, the periods of vibration were compared with those reported by Kappos et al. [32]. High agreement between the natural periods obtained from the OpenSees models and results reported by Kappos was observed.

\section{Earthquake Data}

Nonlinear time-history analyses of the bridges are carried out using 20 sets of broadband bidirectional ground motions with various soil types, magnitudes, and fault distance identified by Baker [33]. The earthquake records have been selected from the Pacific Earthquake Engineering Research (PEER) database. Baker developed a record selection algorithm which results in a set of ground motions whose response spectra match a target mean and variance [33]. Herein, a part of the set of standardized ground motions provided by Baker is used. The ground motions at variable 


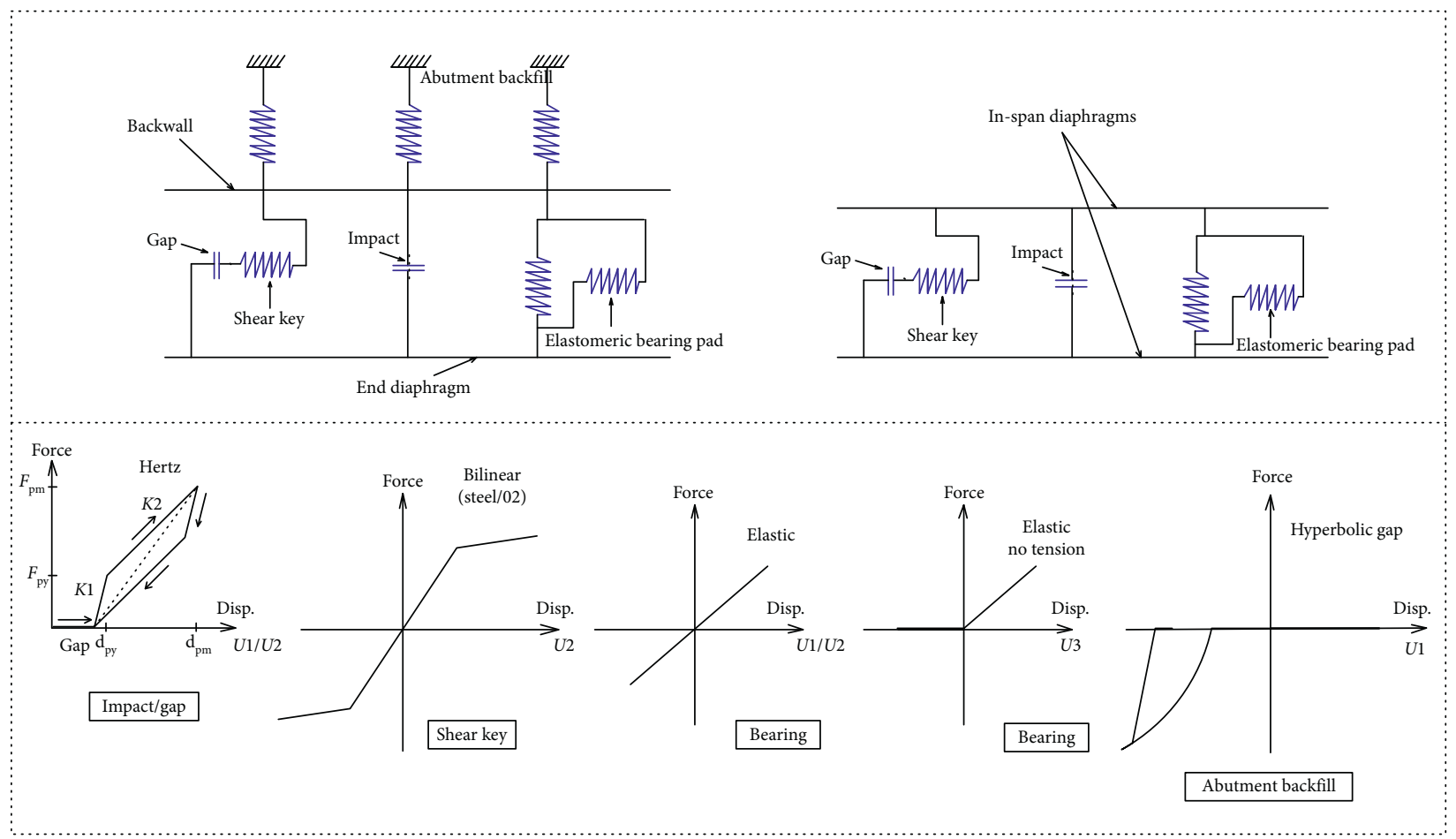

FIGURE 5: In-span hinge and abutment modeling scheme.

TABLE 4: Summary of mechanical and geometrical specifications of bridge components.

\begin{tabular}{lcc}
\hline Modeling parameter & Units & Values \\
\hline Steel yield strength & $\mathrm{MPa}$ & 400 \\
Concrete unconfined strength & $\mathrm{MPa}$ & 25 \\
Elastomeric bearing shear modulus & $\mathrm{MPa}$ & 0.9 \\
Abutment passive initial stiffness & $\mathrm{KN} / \mathrm{mm} / \mathrm{m}$ & 14.5 \\
Damping & - & $\mathrm{Mm}$ \\
Seat width & $\mathrm{Mm}$ & 0.05 \\
Joint gap & $\mathrm{Mm}$ & 150 \\
Bearing (width $\times$ depth $\times$ height) & $\mathrm{Mm}$ & 50 \\
Shear key (width $\times$ depth) & $(\mathrm{KN} / \mathrm{cm})$ & $(600 \times 400 \times 120)(3$ bearings $)$ \\
Transverse stiffness of the in-span shear keys & & $380 \times 380$ \\
\hline
\end{tabular}

distances to the rupture plane with magnitude of $\mathrm{Mw}=6.0$ to 8.0 under stiff soil conditions were selected. The major specifications of the ground motions are listed in Table 5. Figure 6 represents the 5\% damped pseudoacceleration response spectra of selected earthquakes. The individual and averaged horizontal components of the selected ground motions are illustrated. The vertical component of earthquakes is waived in this study.

\section{Evaluation of the Proposed Indices}

6.1. Validation of GRI. To validate the proposed criterion, herein the suggested regularity indices are calculated for all intended models and compared with the results of Calvi index. The RI proposed by Calvi [5] explained in (8) is a reliable criterion which has been used frequently by researchers [11]. The generality of Calvi and other previous methods is based on quantitative criteria for an entire bridge, whereas the sources of irregularity and their distribution along the bridge are not provided. The Calvi index is a measurement of differences between the transverse mode shapes of the deck without columns and the whole bridge based on the orthogonality property of the eigenvectors expressed in the following form:

$$
\mathrm{RI}=\sqrt{\frac{\sum_{i=1}^{n}\left(\varnothing_{i}^{A} M \varnothing_{i}^{B}\right)^{2}}{n}},
$$

where $\varnothing_{i A}, \varnothing_{i B}, M$, and $n$ are the $i^{\text {th }}$ mode shapes of the entire bridge and the deck alone, the mass matrix of the deck, and the number of modes, respectively.

Eighteen bridges are considered in the format of singleand multiframe bridges. The first three transverse modes of vibration are taken into consideration. For instance, the first three transverse modes of deck-alone for class B and model B1221 are shown in Figure 7. The results of the new regularity index (GRI) are compared with those of reliable Calvi method as presented in Table 6. The level of accordance 
TABle 5: Considered earthquake record.

\begin{tabular}{|c|c|c|c|c|c|}
\hline No. & Earthquake name & Year & Station & Magnitude & Closest distance \\
\hline 1 & Mammoth Lakes-01 & 1980 & Long Valley Dam (Upr Abut) & 6.1 & 15.5 \\
\hline 2 & Chi-Chi, Taiwan & 1999 & CHY036 & 7.6 & 16.1 \\
\hline 3 & Cape Mendocino & 1992 & Ferndale Fire Station & 7 & 14.3 \\
\hline 4 & Imperial Valley-06 & 1979 & Delta & 6.5 & 22 \\
\hline 5 & Kocaeli, Turkey & 1999 & Yarimca & 7.5 & 4.8 \\
\hline 6 & Imperial Valley-06 & 1979 & Calipatria Fire Station & 6.5 & 24.6 \\
\hline 7 & Chi-Chi, Taiwan & 1999 & CHY034 & 7.6 & 14.8 \\
\hline 8 & Chi-Chi, Taiwan & 1999 & NST & 7.6 & 38.4 \\
\hline 9 & Kocaeli, Turkey & 1999 & Duzce & 7.5 & 15.4 \\
\hline 10 & Trinidad & 1980 & Rio Dell Overpass, E Ground & 7.2 & 76.06 \\
\hline 11 & Spitak, Armenia & 1988 & Gukasian & 6.8 & 23.99 \\
\hline 12 & Loma Prieta & 1989 & Gilroy Array \#4 & 6.9 & 14.3 \\
\hline 13 & Chi-Chi, Taiwan & 1999 & TCU060 & 7.6 & 8.5 \\
\hline 14 & Victoria, Mexico & 1980 & Chihuahua & 6.3 & 19 \\
\hline 15 & Loma Prieta & 1989 & Fremont-Emerson Court & 6.9 & 39.9 \\
\hline 16 & Chalfant Valley-02 & 1986 & Zack Brothers Ranch & 6.2 & 7.6 \\
\hline 17 & Chi-Chi, Taiwan & 1999 & TCU118 & 7.6 & 26.8 \\
\hline 18 & Denali, Alaska & 2002 & TAPS Pump Station \#10 & 7.9 & 2.7 \\
\hline 19 & Imperial Valley-06 & 1979 & El Centro Array \#4 & 6.5 & 7.1 \\
\hline 20 & Big Bear-01 & 1992 & San Bernardino-E & 6.5 & 34.98 \\
\hline
\end{tabular}

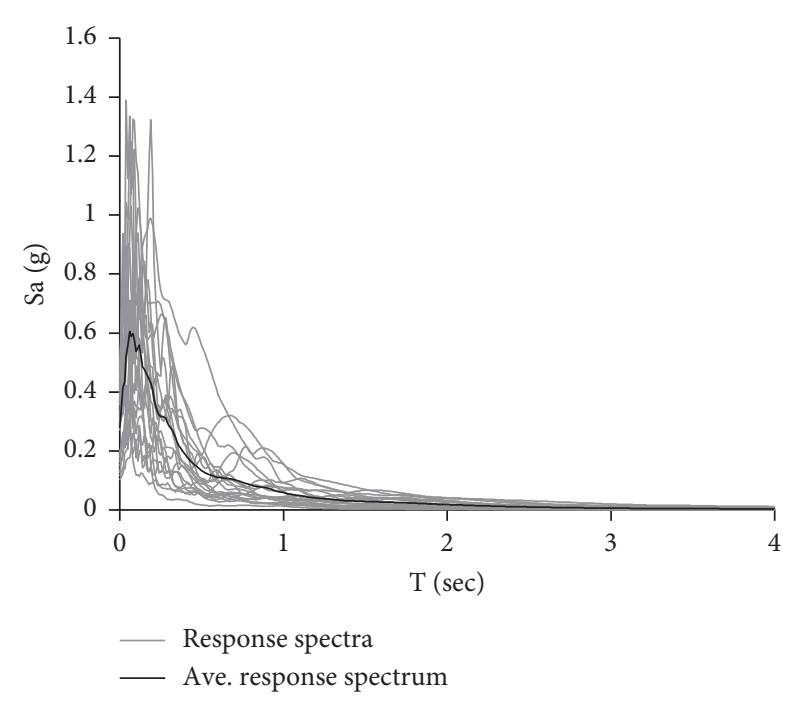

FIGURE 6: Earthquake response spectrum.

between the two methods would determine the validity of the proposed criterion. According to Table 6, it is observed that there is a high correlation between the Calvi and proposed methods. Therefore, the new method is accurate enough so as to be implemented.

6.2. Sensitivity of New RIs to the Number of Required Modes. The GRI is formulated based on the combination of several individual modal shapes results. It is generally believed that the regular bridges have the dominant fundamental mode participation and, with an increase in irregularity, the contribution of higher mode increases. Therefore, it seems that the number of required modes to reach an accurate GRI depends on the irregularity level of the intended bridge. The effects of higher modes of vibration on the GRI values are presented in Figure 8. According to Section 6.1, the models with variable piers height along the bridge (low GRI) are highly irregular (e.g., A131 or B1331 models); therefore, it is expected that, in such cases, the higher modes are associated with considerable effects. Figure 8 confirms this expectation, especially for multiframe bridges. Based on the results, multiframe systems consistently require more number of considered modes to achieve the accurate regularity index compared to continuous frames. This means that higher modes of vibration are of paramount importance in the cases of multiframe bridges and especially irregular ones. On the other hand, Figure 8 reveals that regular bridges with GRI values equal to unity are independent of higher modes; i.e., the results obtained by considering one, two, or more modes of vibration are the same. Therefore the GRI can be calculated based on merely the first mode of vibration.

6.3. Correlation between Proposed Regularity Index and Bridge Irregularity Characteristics. When two variables tend to increase or decrease in tandem, there is a correlation between them. The linear dependency of two random variables is measured by the correlation coefficient. The Pearson correlation coefficient for variables with $\mathrm{N}$ scalar observations is defined as below:

$$
\rho(A, B)=\frac{1}{N-1} \sum_{i=1}^{N}\left(\frac{A_{i}-\mu_{A}}{\sigma_{A}}\right)\left(\frac{B_{i}-\mu_{B}}{\sigma_{B}}\right),
$$

where $\mu_{A}$ and $\sigma_{A}$ are the mean and standard deviation of variable $A$, respectively, and $\mu_{B}$ and $\sigma_{B}$ are the mean and standard deviation of variable $B$. Figure 9 represents the correlation coefficient between the bridge regularity index (GRI) and three substantive irregularity characteristics of a bridge, i.e., maximum adjacent piers stiffness ratio, the minimum number of required vibration modes to achieve $90 \%$ of mass participation ratio, and the coefficient of 


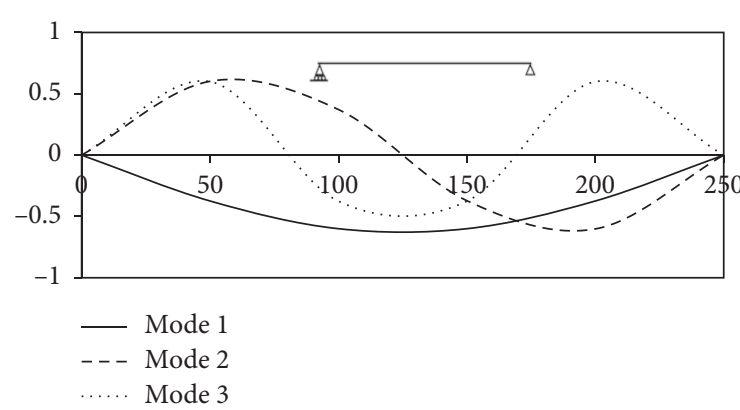

(a)

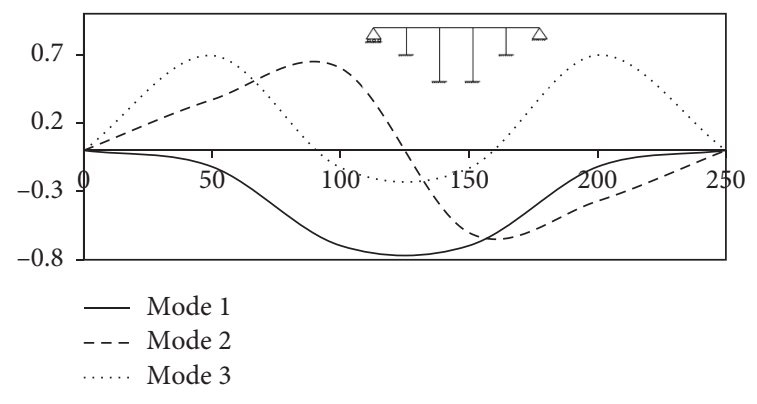

(b)

FiguRE 7: First three transverse modes of vibration model B1221: (a) deck-alone; (b) whole bridge.

TABLE 6: Validation of proposed regularity index.

\begin{tabular}{lcc}
\hline Model & GRI & Calvi method (in (1)) \\
\hline A111 & 1.000 & 1.000 \\
A121 & 0.899 & 0.954 \\
A131 & 0.884 & 0.939 \\
Multi-A111 & 0.887 & 0.940 \\
Multi-A121 & 0.829 & 0.879 \\
Multi-A131 & 0.818 & 0.863 \\
B1111 & 1.000 & 1.000 \\
B1221 & 0.920 & 0.916 \\
B1331 & 0.909 & 0.893 \\
Multi-B1111 & 0.956 & 0.963 \\
Multi-B1221 & 0.886 & 0.841 \\
Multi-B1331 & 0.874 & 0.813 \\
C1111 & 1.000 & 1.000 \\
C1221 & 0.920 & 0.916 \\
C1331 & 0.909 & 0.893 \\
Multi-C1111 & 0.967 & 0.987 \\
Multi-C1221 & 0.890 & 0.867 \\
Multi-C1331 & 0.881 & 0.845 \\
\hline
\end{tabular}

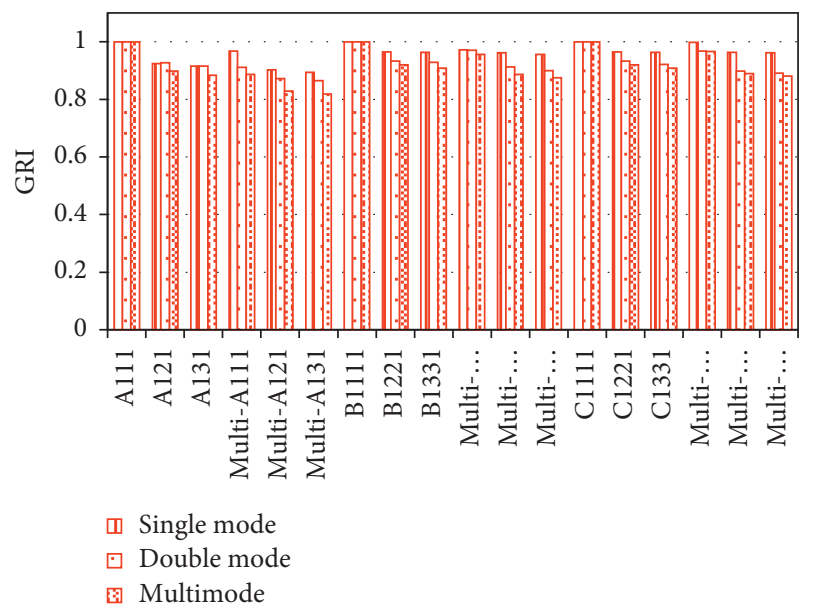

FIGURE 8: GRI based on single, double, and multimode calculation.

variation of piers stiffness. The coefficient of variation $(\mathrm{COV})$ of piers stiffness along the bridge is defined as the ratio of the standard deviation to the mean of columns stiffness for an individual bridge. The low value of COV denotes the column uniform stiffness and vice versa.

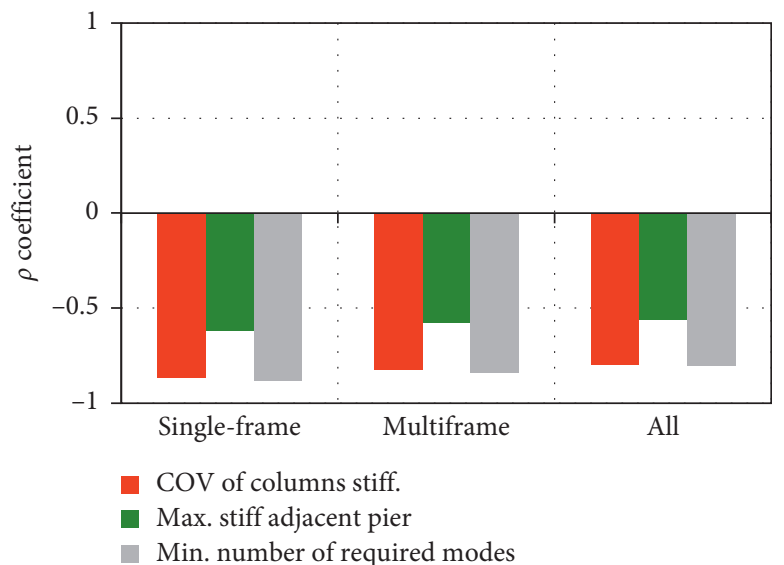

FIGURE 9: Correlation between the GRI and bridge irregularity characteristics.

As expected, correlations between the GRI and irregularity characteristics are negative for all models. In general, an increment in GRI is associated with diminished maximum pier stiffness ratios, minimum number of required vibration mode, and $\mathrm{COV}$ of piers stiffness. According to Figure 9, the COV of piers stiffness and the minimum number of required vibration modes represent a stronger negative correlation with GRI than the third characteristic. Therefore, it is concluded that to increase the regularity of a bridge, it is very effective to provide column uniform stiffness.

\section{Application of Proposed Indices}

7.1. Detection of Local Regularity in Viaduct-Type Bridges. As mentioned previously, one aim of this research is to determine the quantitative values of regularity at different parts of bridges. The local regularity index for each considered DOF was derived based on (1)-(6). The interest nodes considered are at top of the piers at the junction with the deck. The global regularity index is then calculated using (7). The results of LRI and GRI for all intended bridges are summarized in Tables 7 and 8 for classes A, B, and C. As stated before, the LRI and GRI values both range from zero to one. The values of the LRI and GRI are found to be equal to 1 for regular single-frame models, e.g., A111 and B1111. 
Table 7: Global and local regularity index for A models.

\begin{tabular}{|c|c|c|c|c|c|c|c|}
\hline \multirow{3}{*}{$\begin{array}{l}\text { Model } \\
\text { A111 }\end{array}$} & \multirow{2}{*}{$\begin{array}{c}\text { Regularity index } \\
\text { LRI }\end{array}$} & \multicolumn{3}{|c|}{ Single-frame } & \multicolumn{3}{|c|}{ Multiframe } \\
\hline & & \multirow[t]{2}{*}{$\begin{array}{c}P_{1} \\
1.0000\end{array}$} & $\begin{array}{c}P_{2} \\
1.0000\end{array}$ & \multirow[t]{2}{*}{$\begin{array}{c}P_{3} \\
1.0000\end{array}$} & \multirow[t]{2}{*}{$\begin{array}{c}P_{1} \\
0.845\end{array}$} & $\begin{array}{c}P_{2} \\
0.941\end{array}$ & \multirow[t]{2}{*}{$\begin{array}{c}P_{3} \\
0.872\end{array}$} \\
\hline & GRI & & 1.0000 & & & 0.8866 & \\
\hline \multirow[t]{2}{*}{ A121 } & LRI & \multirow[t]{2}{*}{$\begin{array}{c}P_{1} \\
0.9209\end{array}$} & $\begin{array}{c}P_{2} \\
0.8521\end{array}$ & \multirow[t]{2}{*}{$\begin{array}{c}P_{3} \\
0.9209\end{array}$} & \multirow[t]{2}{*}{$\begin{array}{c}P_{1} \\
0.818\end{array}$} & $\begin{array}{c}P_{2} \\
0.805\end{array}$ & \multirow[t]{2}{*}{$\begin{array}{c}P_{3} \\
0.864\end{array}$} \\
\hline & GRI & & 0.8986 & & & 0.8290 & \\
\hline \multirow[t]{2}{*}{ A131 } & LRI & \multirow[t]{2}{*}{$\begin{array}{c}P_{1} \\
0.9091\end{array}$} & $\begin{array}{c}P_{2} \\
0.8304\end{array}$ & \multirow[t]{2}{*}{$\begin{array}{c}P_{3} \\
0.9091\end{array}$} & $\begin{array}{c}P_{1} \\
0.808\end{array}$ & $\begin{array}{c}P_{2} \\
0.787\end{array}$ & \multirow[t]{2}{*}{$\begin{array}{c}P_{3} \\
0.857\end{array}$} \\
\hline & GRI & & 0.8837 & & & 0.8179 & \\
\hline
\end{tabular}

TABLE 8: Global and local regularity index for B and C models.

\begin{tabular}{|c|c|c|c|c|c|c|c|c|c|}
\hline Model & Regularity index & \multicolumn{4}{|c|}{ Single-frame } & \multicolumn{4}{|c|}{ Multiframe } \\
\hline \multirow[t]{2}{*}{ B1111 } & LRI & $\begin{array}{c}P_{1} \\
1.000\end{array}$ & $\begin{array}{c}P_{2} \\
1.000\end{array}$ & $\begin{array}{c}P_{3} \\
1.000\end{array}$ & $\begin{array}{c}P_{4} \\
1.000\end{array}$ & $\begin{array}{c}P_{1} \\
0.950\end{array}$ & $\begin{array}{c}P_{2} \\
0.982\end{array}$ & $\begin{array}{c}P_{3} \\
0.925\end{array}$ & $\begin{array}{c}P_{4} \\
0.966\end{array}$ \\
\hline & GRI & \multicolumn{4}{|c|}{1.0000} & \multicolumn{4}{|c|}{0.9559} \\
\hline \multirow[t]{2}{*}{ B1221 } & LRI & $\begin{array}{c}P_{1} \\
0.905\end{array}$ & $\begin{array}{c}P_{2} \\
0.935\end{array}$ & $\begin{array}{c}P_{3} \\
0.936\end{array}$ & $\begin{array}{c}P_{4} \\
0.905\end{array}$ & $\begin{array}{c}P_{1} \\
0.826\end{array}$ & $\begin{array}{c}P_{2} \\
0.915\end{array}$ & $\begin{array}{c}P_{3} \\
0.911\end{array}$ & $\begin{array}{c}P_{4} \\
0.889\end{array}$ \\
\hline & GRI & \multicolumn{4}{|c|}{0.9204} & \multicolumn{4}{|c|}{0.8860} \\
\hline \multirow[t]{2}{*}{ B1331 } & LRI & $\begin{array}{c}P_{1} \\
0.888\end{array}$ & $\begin{array}{c}P_{2} \\
0.929\end{array}$ & $\begin{array}{c}P_{3} \\
0.929\end{array}$ & $\begin{array}{c}P_{4} \\
0.888\end{array}$ & $\begin{array}{c}P_{1} \\
0.811\end{array}$ & $\begin{array}{c}P_{2} \\
0.909\end{array}$ & $\begin{array}{c}P_{3} \\
0.905\end{array}$ & $\begin{array}{c}P_{4} \\
0.869\end{array}$ \\
\hline & GRI & \multicolumn{4}{|c|}{0.9087} & \multicolumn{4}{|c|}{0.8744} \\
\hline \multirow[t]{2}{*}{ C1111 } & LRI & $\begin{array}{c}P_{1} \\
1.000\end{array}$ & $\begin{array}{c}P_{2} \\
1.000\end{array}$ & $\begin{array}{c}P_{3} \\
1.000\end{array}$ & $\begin{array}{c}P_{4} \\
1.000\end{array}$ & $\begin{array}{c}P_{1} \\
0.960\end{array}$ & $\begin{array}{c}P_{2} \\
0.974\end{array}$ & $\begin{array}{c}P_{3} \\
0.974\end{array}$ & $\begin{array}{c}P_{4} \\
0.960\end{array}$ \\
\hline & GRI & \multicolumn{4}{|c|}{1.0000} & \multicolumn{4}{|c|}{0.9668} \\
\hline \multirow[t]{2}{*}{ C1221 } & LRI & $\begin{array}{c}P_{1} \\
0.905\end{array}$ & $\begin{array}{c}P_{2} \\
0.935\end{array}$ & $\begin{array}{c}P_{3} \\
0.936\end{array}$ & $\begin{array}{c}P_{4} \\
0.905\end{array}$ & $\begin{array}{c}P_{1} \\
0.849\end{array}$ & $\begin{array}{c}P_{2} \\
0.929\end{array}$ & $\begin{array}{c}P_{3} \\
0.929\end{array}$ & $\begin{array}{c}P_{4} \\
0.849\end{array}$ \\
\hline & GRI & \multicolumn{4}{|c|}{0.9204} & \multicolumn{4}{|c|}{0.8897} \\
\hline \multirow[t]{2}{*}{ C1331 } & LRI & $\begin{array}{c}P_{1} \\
0.888\end{array}$ & $\begin{array}{c}P_{2} \\
0.929\end{array}$ & $\begin{array}{c}P_{3} \\
0.929\end{array}$ & $\begin{array}{c}P_{4} \\
0.888\end{array}$ & $\begin{array}{c}P_{1} \\
0.834\end{array}$ & $\begin{array}{c}P_{2} \\
0.925\end{array}$ & $\begin{array}{c}P_{3} \\
0.925\end{array}$ & $\begin{array}{c}P_{4} \\
0.834\end{array}$ \\
\hline & GRI & \multicolumn{4}{|c|}{0.9087} & \multicolumn{4}{|c|}{0.8807} \\
\hline
\end{tabular}

The models referred to as A121, A131, B1221, and B1331 represent particular types of bridges where central piers are taller than side ones. In such cases, with increasing the middle to side piers height ratio, the regularity index decreases and the intended bridges become more irregular. A minimum range cannot be defined for those parameters because the numerical study was made with only a few values of LRI and GRI.

The results show that, in majority of cases, multiframe bridges are at least slightly more irregular than the singleframe one. According to Tables 7 and 8 , it is concluded that the difference between RI values in single and comparable multiframe bridges is more remarkable in the cases of regular bridges than that of irregular ones. In other words, the in-span hinge affects the regular bridges more than the irregular ones. This result proves that the in-span hinges are the main source of irregularity. Among all considered bridges, the two-frame models of A131 and B1331, which consist of one in-span hinge, represent the minimum values of GRI. Therefore, these models are categorized as the most irregular bridges considered in this study. Another important observation regarding Tables 7 and 8 is that the GRI values for multiframe bridges of class $\mathrm{C}$ are more than two-frame models of class $\mathrm{B}$; i.e., the regularity degree of class $\mathrm{C}$ bridges with two in-span hinges is more than similar bridges with one hinge. In addition, according to the AASHTO provisions, the maximum stiffness ratios of adjacent piers for models A131 and B1331 are exactly identical; therefore, AASHTO categorizes both mentioned models in the same irregularity category. However, based on proposed quantitative criterion, the model A131 is more irregular than B1331. In fact, AASHTO considers merely the stiffness ratio of adjacent frames. Consequently, a quantitative index such as GRI and LRI with the capability of considering this difference is necessary for estimating the actual degree of irregularity.

Graphical view of LRI is shown in Figure 10. Based on Figure 10(b), two and three-frame bridges are representative of class B and class $\mathrm{C}$ multiframe models, respectively. As is illustrated in Figure 10, the LRI diagram represents the regularity distribution along the bridge. It reveals some extreme points with the lowest values of regularity as well. These points are referred to as the irregularity sources. In the classes of A121 and A131, the middle pier is associated with the minimum value of local regularity index, which is considered as an irregularity source in both single- and multiframe bridges. On the contrary, in A111 multiframe model, the left pier offers the minimum value of LRI; therefore this pier is a source of irregularity. To achieve a 

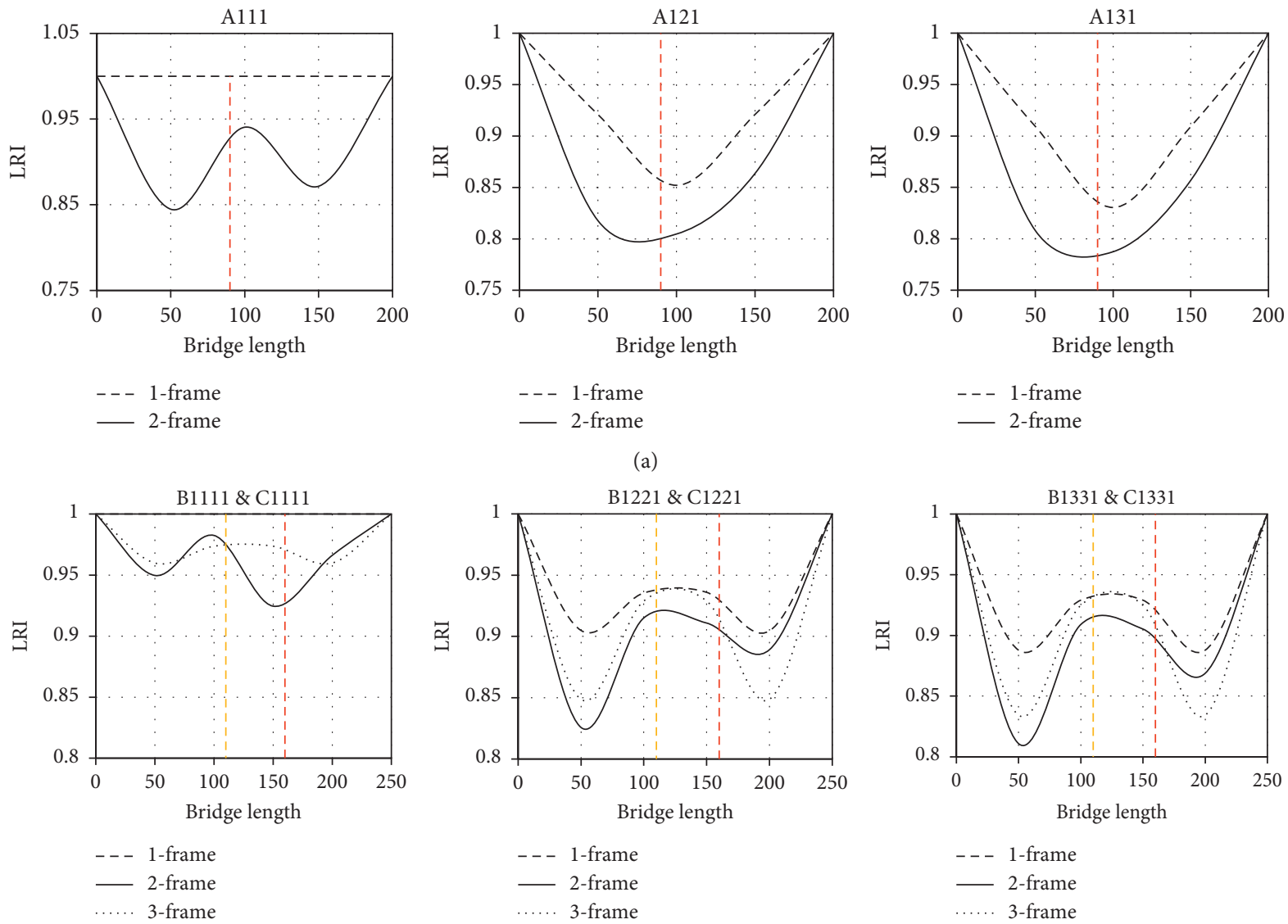

(b)

Figure 10: Proposed local regularity index: (a) class A; (b) class B and class C.

better performance, it is recommended that stiffness of piers be adjusted so that the values of LRI become more uniform. According to Figure 10, in the case of multiframe bridges, the pier which is single-pier in a frame is an irregularity source. The LRI appears to be a suitable criterion for the recognition of sources of irregularity. In addition, it facilitates proper positioning of the in-span hinge. It is recommended to calculate LRI prior to analysis and design of bridges and update it during the process of design. Thus, the designer could be able to select an appropriate section for each pier so as to have a regular bridge with the most uniform demand.

7.2. Nonlinear to Linear Demand Ratio (NLDR). Seismic design codes present the analysis method based on the irregularity of bridges. To evaluate this way of determining the analysis method, herein, the correlation between regularity level and demand values under linear and nonlinear timehistory analyses is assessed.

All intended bridges are analyzed in both longitudinal and transverse directions. Regarding a suit of 20 earthquake records selected for this research project, a total of 720 nonlinear timehistory analyses were performed. In what follows, the NLDR is calculated for all considered bridges at each pier; afterwards, the relation between NLDR and RI will be investigated. The dispersion of the results has been depicted in terms of minimum, median, average, and maximum values in Figure 11.

Figure 11 illustrates the nonlinear to linear displacement ratio in the longitudinal direction. It confirms that in the case of regular bridges the NDLR approaches 1. According to the results, in the cases of extremely irregular bridges (low regularity index), the elastic responses are considerably different from the actual nonlinear responses and maximum inelastic to elastic displacement ratio is greater than 1 . As the irregularity decreases, the linear responses approach more realistic nonlinear response. It can be seen that the distribution of seismic demands is more uniform in regular bridges than irregular ones. Also, the results have more dispersion in irregular and multiframe bridges.

Nonlinear and linear displacements in the transverse direction are illustrated in Figures 12 and 13 for classes A, B, and $\mathrm{C}$ models. Based on the figures and similar to the longitudinal direction, in the case of the extremely irregular bridge (models A131, B1331, and C1331), the elastic transverse responses are markedly different from the actual nonlinear responses. In other words, if the GRI decreases, then the NLDR gets far from unity, either more or less than unity. Consequently, it can be inferred that GRI and NLDR are correlated. Using the correlation of GRI and NLDR, the designer could find out whether 


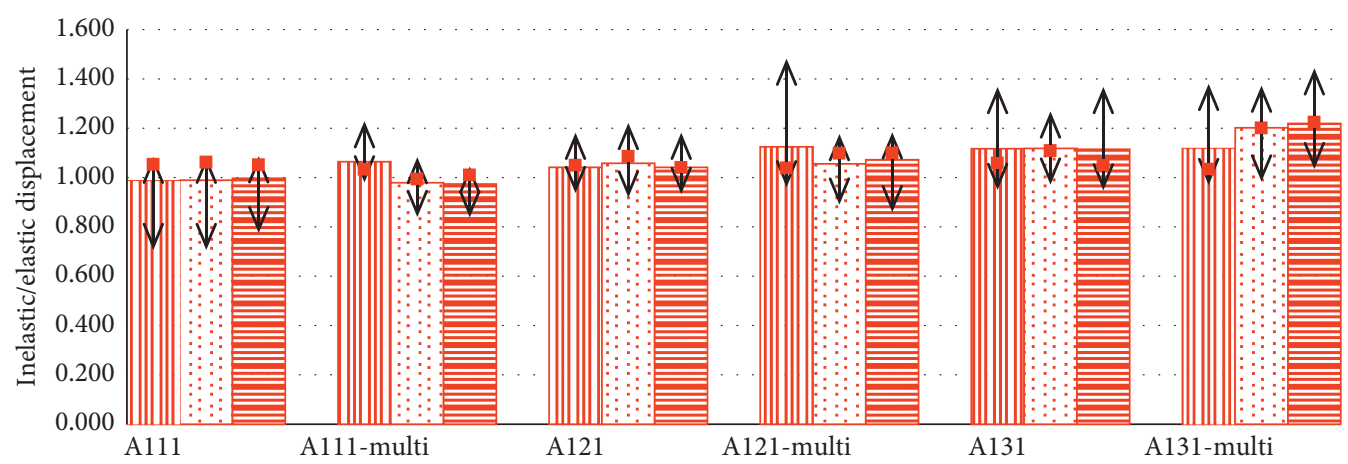

- Median

(a)

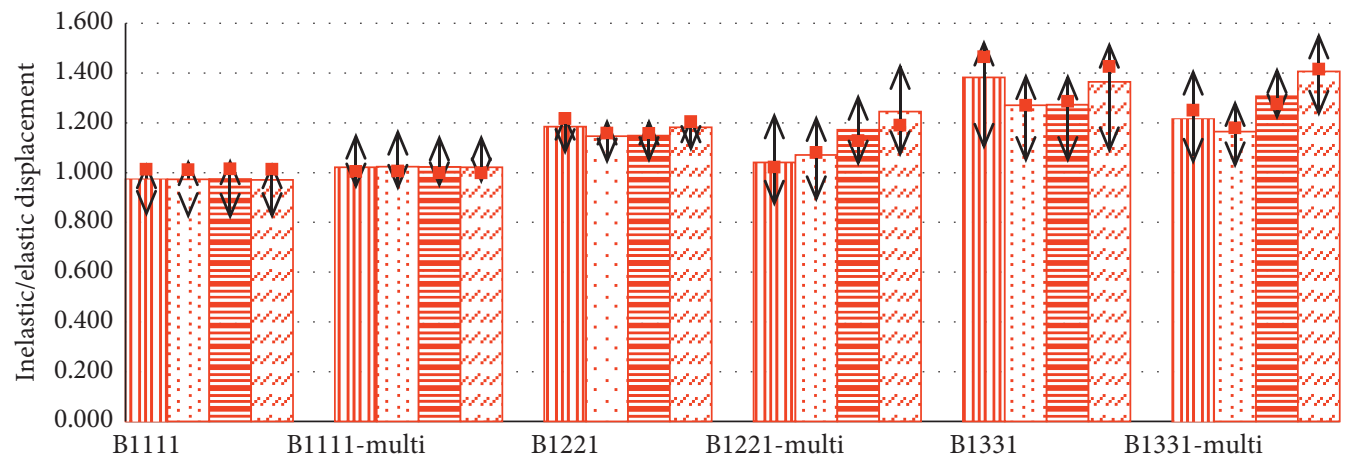

- Median

(b)

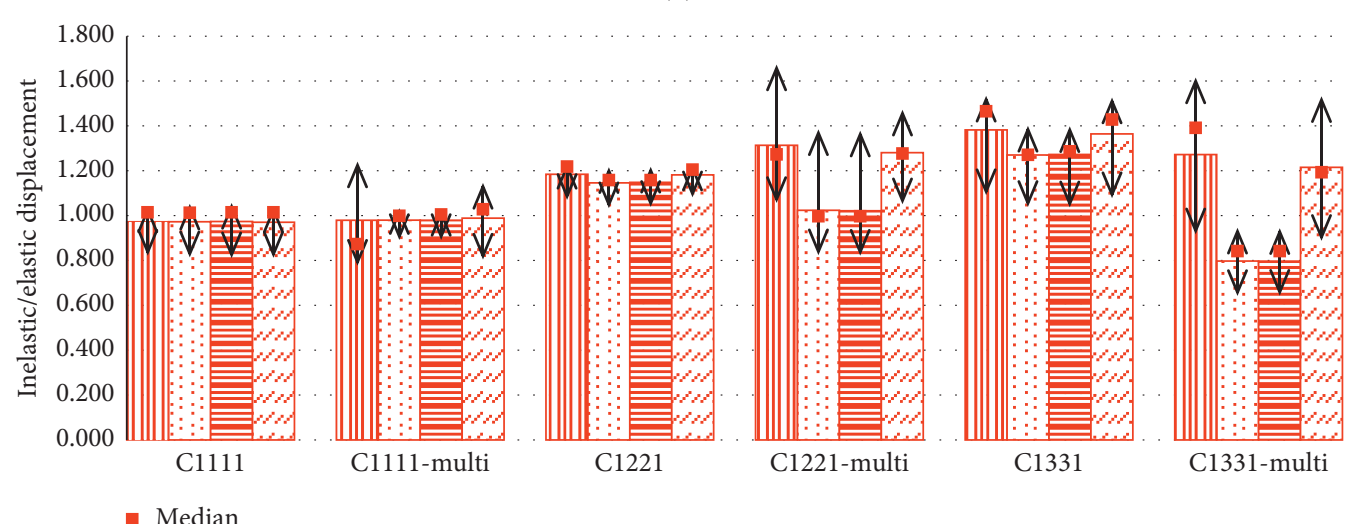

(c)

Figure 11: Inelastic/elastic longitudinal displacement: (a) class A; (b) class B; (c) class C.

the linear analysis is able to represent accurate responses of the bridge or nonlinear analysis is required. Generally, the NLDR for regular single-frame bridges is closer to unity than those of multiframe ones. Results reveal that, by increasing the irregularity of bridge, the difference between responses of singleand multiframe bridges increases. The most difference belongs to the tallest pier. According to the findings, piers represent more nonlinear behavior in the transverse direction than the longitudinal direction; it could be interpreted by the different behavior of a bridge in the longitudinal and transverse direction which are frame and cantilever behavior, respectively. As depicted in Figures 12 and 13, the distribution of demands among different piers in the longitudinal direction is more uniform than the transverse direction.

It has been observed that using elastic analysis leads to a more nonconservative design in high irregular (low GRI) and particularly multiframe bridges, e.g., models A131, B1331, and C1331. Consequently, the results indicate that the recommendations of the codes for analysis methods can only be applied when the bridges are single-frame. 

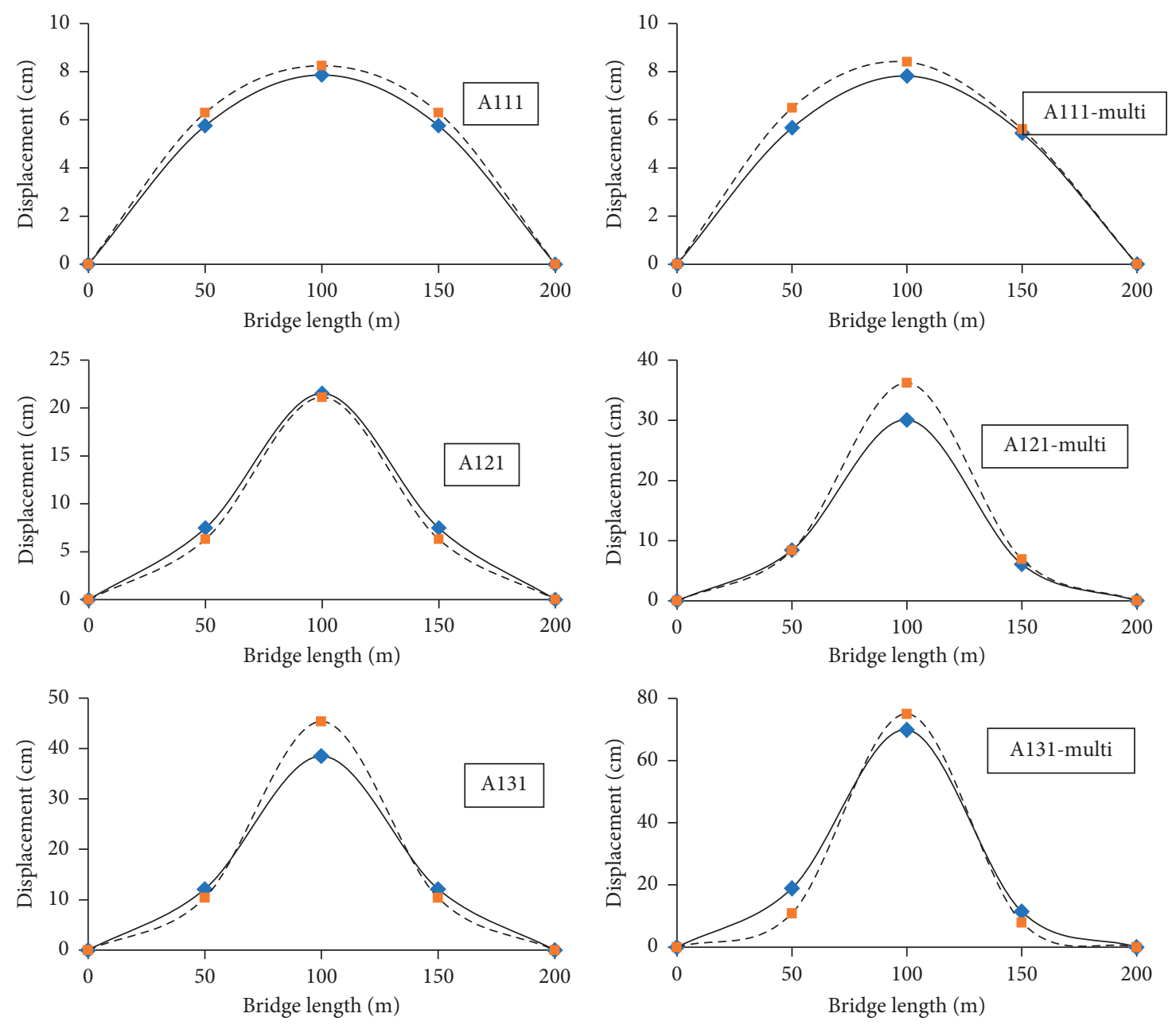

Figure 12: Inelastic (dashed line) and elastic (solid line) transverse displacement: class A.

Therefore, it is conservatively recommended to perform nonlinear analysis for irregular multiframe bridges.

\subsection{Correlation between the Proposed Local Regularity Index} and Appropriate Analysis Method. As mentioned in Sections $6-4$, the NLDR and GRI are highly correlated. Therefore, the GRI is capable of determining whether linear analysis can yield the maximum displacements of a structure or not. Figures 14 and 15 illustrate the proposed local regularity indices versus the NLDR in longitudinal and transverse directions, respectively. It is clear that there is a specific trend between the values of LRI and the ratio of displacements. The overall trend of scattered data is specified by upper bound and lower bound lines. Generally speaking, the upper and lower bound lines converge when LRI approaches unity; conversely, when LRI decreases, the difference of inelastic and elastic displacement increases; i.e., the NLDR gets far from unity. As is illustrated in Figures 14 and 15, when the local regularity index is less than about 0.95 , and the difference between linear and nonlinear displacement significantly increases. Consequently, it is recommended to use the nonlinear analysis in the cases of LRI more than 0.95 . The same trend is observed for global regularity indices. Since the LRI and the NLRD are correlated, LRI could determine whether the nonlinear analysis is needed for the intended bridge or the linear analysis could represent acceptable results. Nonlinear analysis is a time-consuming process, while calculating the LRI can be simply performed based on modal analysis. Therefore, the GRI and LRI are the most useful indicator to determine an appropriate method of analysis. 

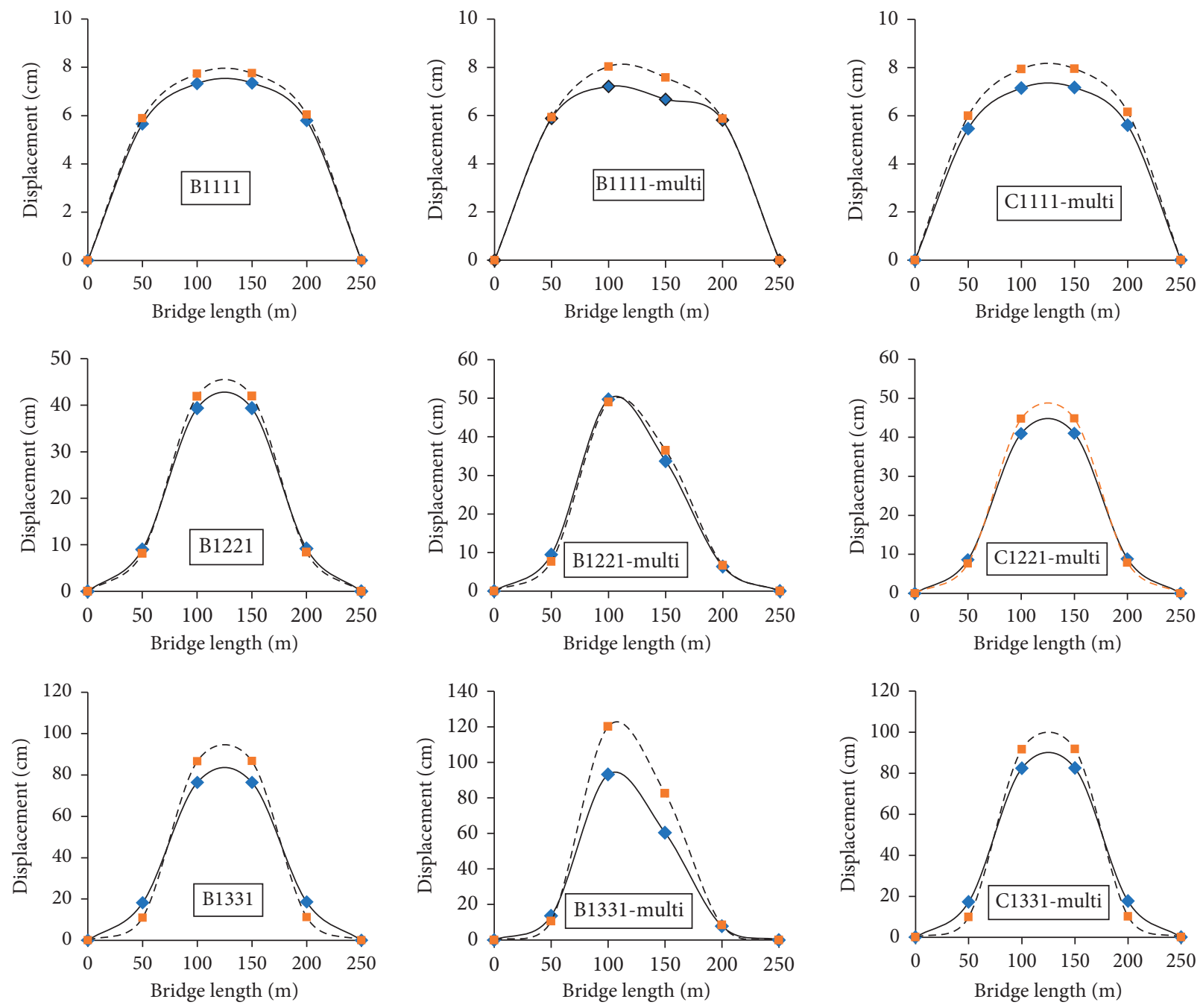

Figure 13: Inelastic (dashed line) and elastic (solid line) transverse displacements: classes B and C.

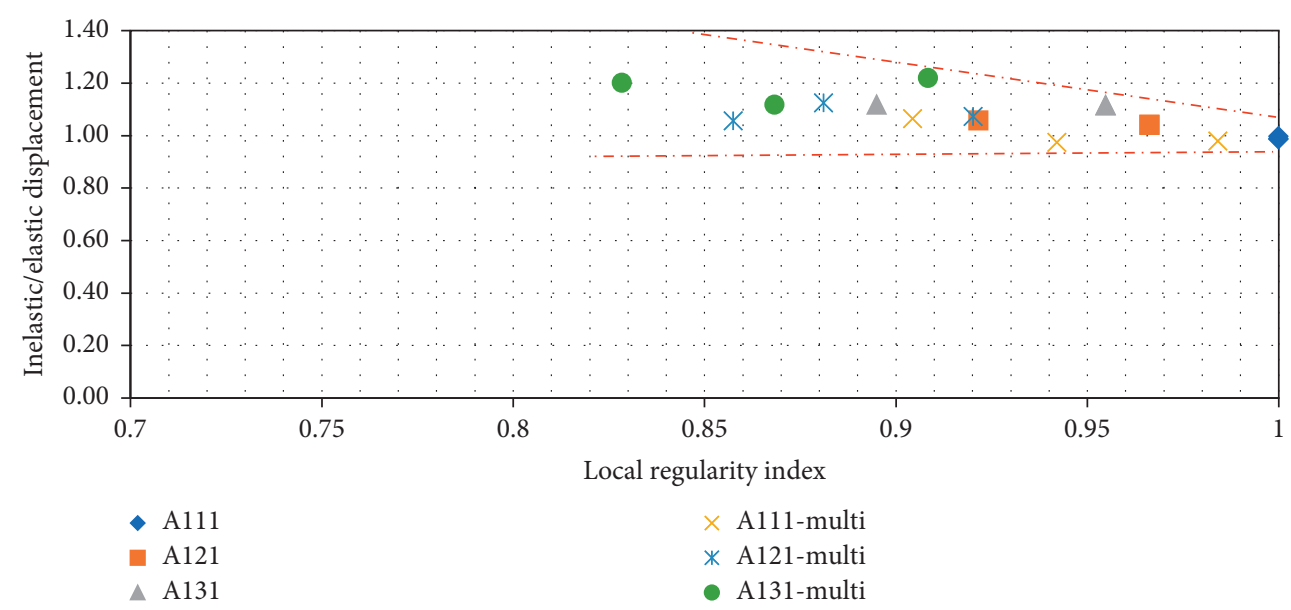

(a)

FIgURE 14: Continued. 


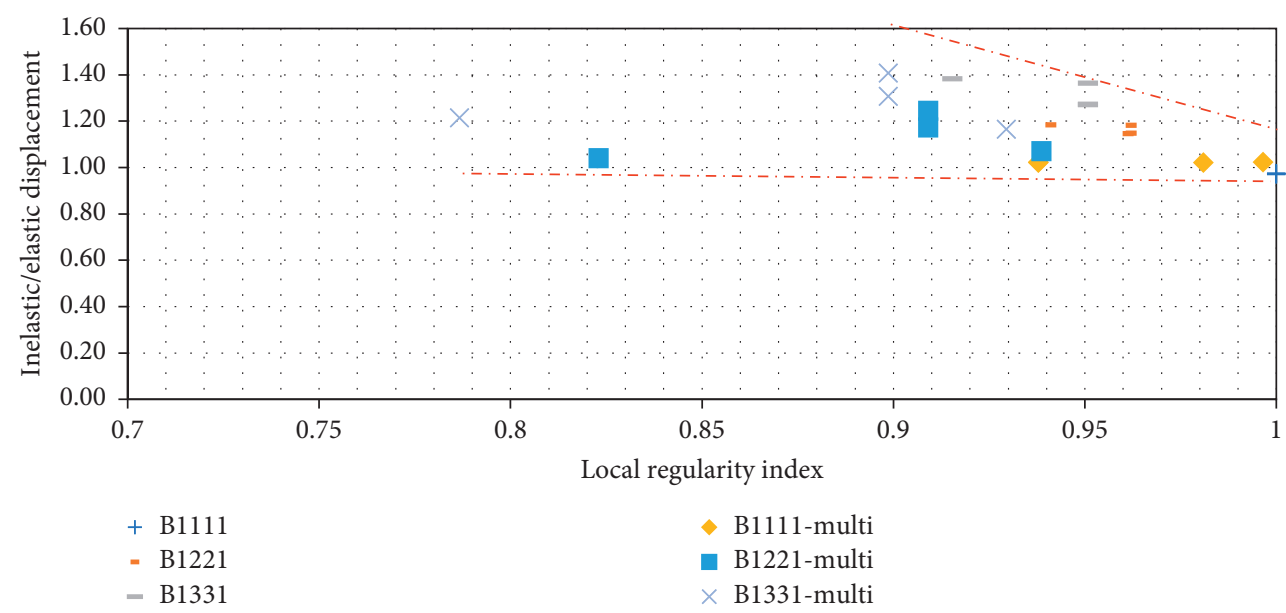

(b)

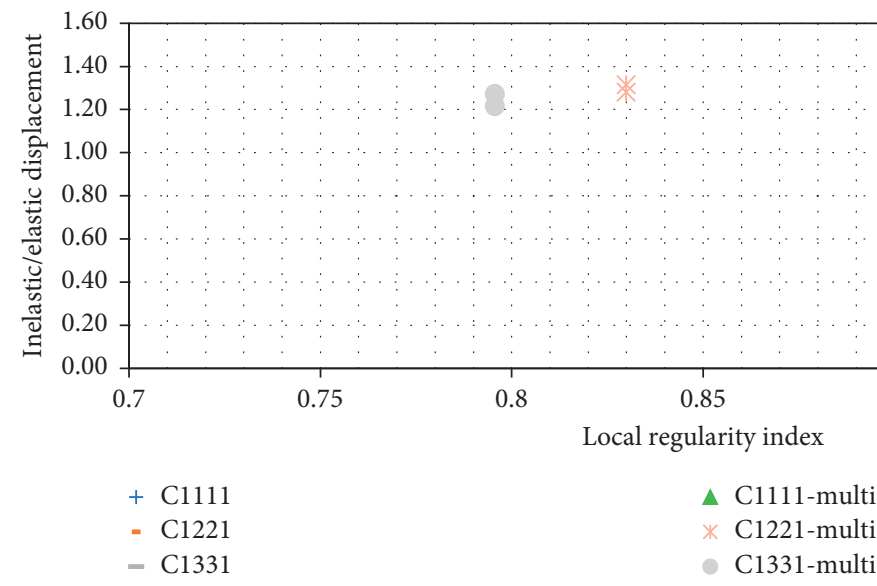

(c)

FIGURE 14: Local regularity index versus the ratio of the longitudinal displacements obtained using inelastic and elastic analysis: (a) class A; (b) class B; (c) class C.

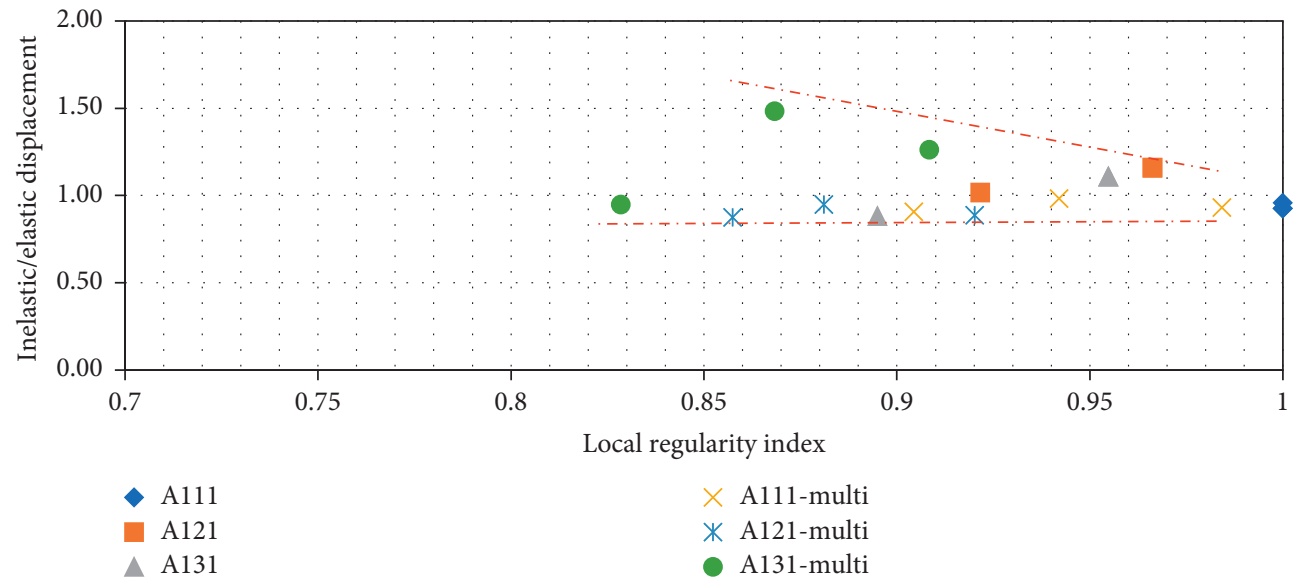

(a)

Figure 15: Continued. 


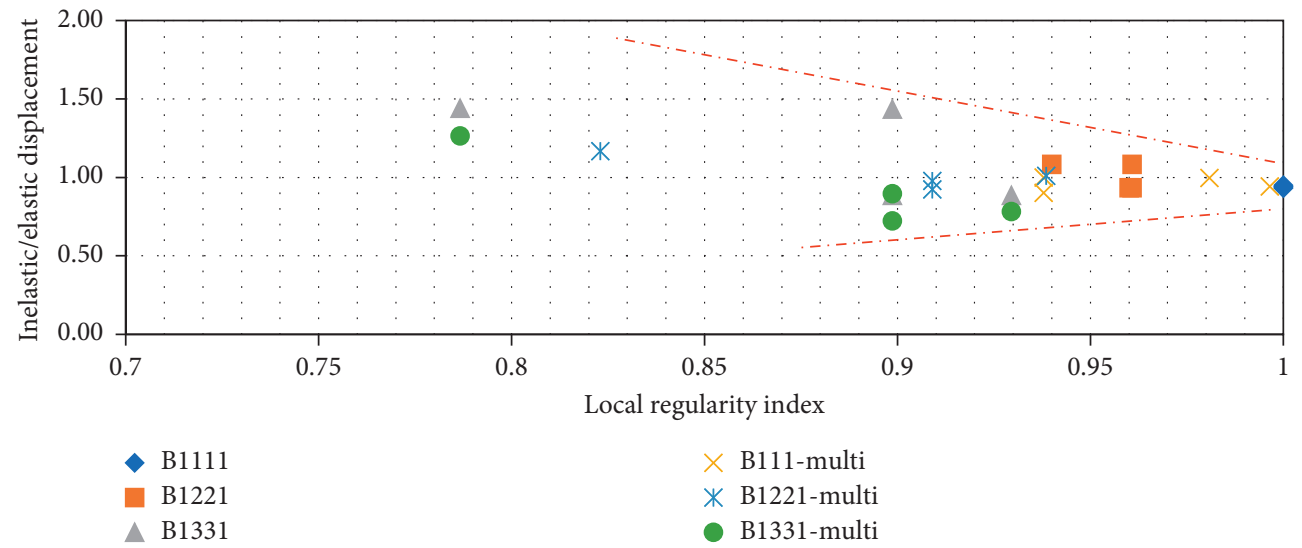

(b)

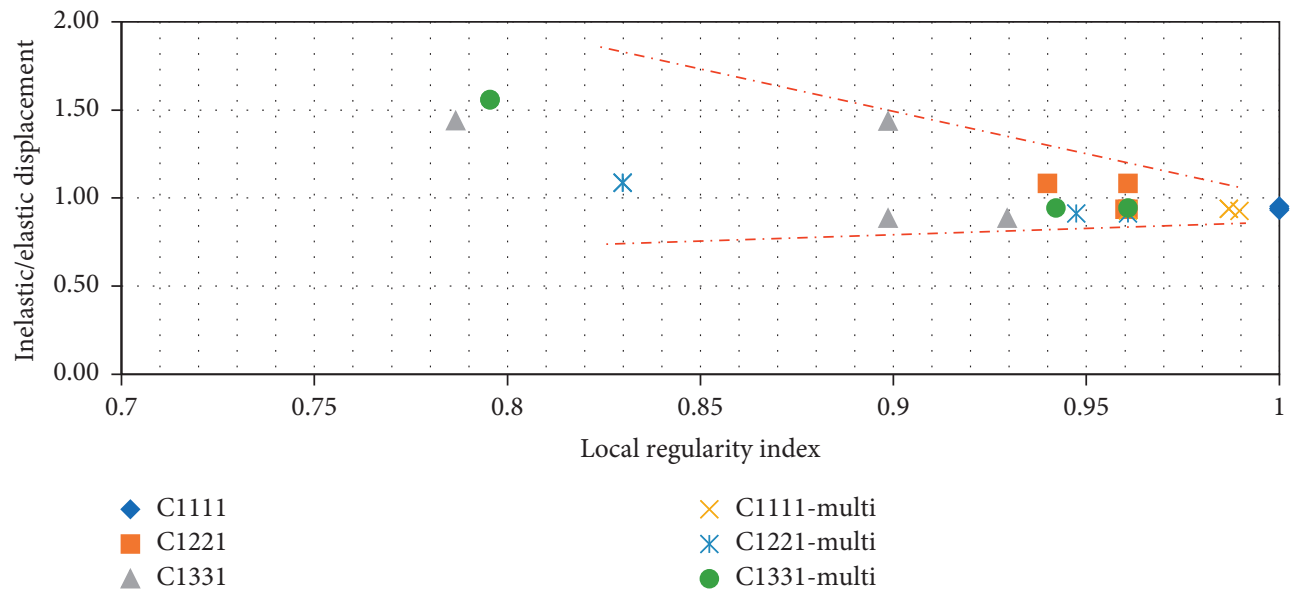

(c)

FIGURE 15: Local regularity index versus the ratio of the transverse displacements obtained using inelastic and elastic analysis: (a) class A; (b) class B; (c) class C.

\section{Summary and Conclusions}

Regarding the scalar definitions of the bridge regularity criteria, up till now there has been no vector criterion representing the distribution of irregularity along the bridge length and determining the source of irregularity, especially in multiframe ones. Therefore, this research project introduced the notion and formulation of local regularity index of bridges. The proposed criteria, referred to as GRI and LRI here, are based on the modified concept of correlation function for spatial locations of scaled mode shapes between deck-alone and entire bridge in the field of experimental vibration analysis. It was shown that the proposed method presents reliable and accurate results. To illustrate the potential of the proposed regularity index, eighteen types of bridges with various number of spans, piers height, and inspan hinge location were considered in both cases of singleand multiframe bridges. The conclusions derived from this survey are outlined as follows.

(i) The current study shows that the new extended regularity index could be used for a variety of purposes, including the detection of sources of irregularity, choosing the proper analysis method, and positioning the in-span hinges, as well as estimating the nonlinear to linear demand ratio at different parts of the bridge.

(ii) Regarding the results, this research confirms that the multiframe bridges are associated with less values of GRI and LRI in comparison with their single-frame counterparts. Consequently, it seems that the design codes need to be modified so as to consider the existence of in-span hinges in the irregularity classification and the selection of analysis method.

(iii) It was found that, among the irregularity parameters of bridges, the coefficient of variation of piers stiffness and the minimum number of required modes to reach $90 \%$ of the mass participation ratio represent higher negative correlation with GRI. Also, according to the results, multiframe systems consistently require more number of modes to achieve an accurate regularity index compared to continuous frames. Therefore, the effects of the 
higher modes and the level of irregularity need to be taken into account in the analysis and design of such bridges.

(iv) According to the results, it is concluded that in-span hinges affect the regular bridges more dramatically than the irregular ones. The results prove that the inspan hinges are one of the main sources of irregularity.

(v) Regarding seismic demand, the maximum nonlinear to linear displacement ratio (NLDR) has a high negative correlation with LRI and GRI. In the case of regular bridges, the NLDR approaches unity, while as the bridge irregularity index increases the elastic and inelastic responses get far from each other. Thus, simple linear analysis method typically fails to estimate the accurate seismic responses of irregular bridges. Accordingly, calculating the GRI and LRI prior to the main analysis could help to select the appropriate method of analysis.

It should be noted that it is not intended to generalize these results to all type of bridges, but making similar results for other cases is possible.

\section{Data Availability}

The data used to support the findings of this study are included within the article. The data include the structural parameters, ground motion inputs, calculation methods, and calculation results.

\section{Conflicts of Interest}

The authors declare that they have no conflicts of interest.

\section{References}

[1] H. Rezaei, S. A. Moayyedi, and R. Jankowski, "Probabilistic seismic assessment of RC box-girder highway bridges with unequal-height piers subjected to earthquake-induced pounding," Bulletin of Earthquake Engineering, vol. 18, no. 4, pp. 1547-1578, 2020.

[2] F. Soleimani, B. Vidakovic, R. DesRoches, and J. Padgett, "Identification of the significant uncertain parameters in the seismic response of irregular bridges," Engineering Structures, vol. 141, pp. 356-372, 2017.

[3] M. C. Gómez-Soberón et al., "Seismic vulnerability through drift assessment for bridges with geometrical irregularities," European Journal of Environmental and Civil Engineering, vol. 2020, Article ID 1686428, 14 pages, 2019.

[4] Aashto, AASHTO LRFD Bridge Design Specifications, American Association of State Highway and Transportation Officials, [2020], Washington, DC, USA, 9th edition, 2020.

[5] G. Calvi, Experimental and Numerical Investigations on the Seismic Response of Bridges and Recommendations for Code Provisions, Laboratório Nacional de Engenharia Civil, Lisbon, Portugal, 1996.

[6] D. Ewins, "Modal testing: theory, practice and application," Mechanical engineering research studies, Vol. 2, Research Studies Press, Hertfordshire, UK, 2000.
[7] R. Akbari and S. Maalek, "Adequacy of the seismic analysis methods for single-column-bent viaducts considering regularity and higher modes effects," Journal of Vibration and Control, vol. 16, no. 6, pp. 827-852, 2010.

[8] M. Grendene, P. Franchetti, and C. Modena, "Regularity criteria for RC and PRC multispan continuous bridges," Journal of Bridge Engineering, vol. 17, no. 4, pp. 671-681, 2012.

[9] P. Tehrani and D. Mitchell, "Effects of column and superstructure stiffness on the seismic response of bridges in the transverse direction," Canadian Journal of Civil Engineering, vol. 40, no. 8, pp. 827-839, 2013.

[10] M. Kohrangi, R. Bento, and M. Lopes, "Seismic performance of irregular bridges-comparison of different nonlinear static procedures," Structure and Infrastructure Engineering, vol. 11, no. 12, pp. 1632-1650, 2015.

[11] R. Akbari and S. Maalek, "A review on the seismic behaviour of irregular bridges," Proceedings of the Institution of Civil Engineers-Structures and Buildings, vol. 171, no. 7, pp. 552580, 2018.

[12] M. Sajed and P. Tehrani, "Investigating the effects of combinations of irregularities on seismic ductility demands and mean response for four-span RC bridges considering displacement direction," Bridge Structures, vol. 16, no. 2-3, pp. 105-117, 2020.

[13] M. Abbasi and M. A. Moustafa, "Probabilistic seismic assessment of as-built and retrofitted old and newly designed skewed multi-frame bridges," Soil Dynamics and Earthquake Engineering, vol. 119, pp. 170-186, 2019.

[14] M. Mehr and A. E. Zaghi, "Seismic response of multi-frame bridges," Bulletin of Earthquake Engineering, vol. 14, no. 4, pp. 1219-1243, 2016.

[15] E. Aboutorabian and M. Raissi Dehkordi, "Numerical study of seismic response of irregular multi-frame reinforced concrete bridges," Proceedings of the Institution of Civil EngineersStructures and Buildings, vol. 173, no. 11, pp. 783-798, 2020.

[16] P. Tehrani and R. Ghanbari, "Investigating different methods for application of earthquake records in seismic evaluation of irregular RC bridges considering incident angles," in Structurevol. 32, Elsevier, 2021.

[17] G. Ayala and M. A. Escamilla, "Modal irregularity in continuous reinforced concrete bridges. Detection, effect on the simplified seismic performance evaluation and ways of solution," in Seismic Behaviour and Design of Irregular and Complex Civil Structures, pp. 103-118, Springer, Dordrecht, Netherlands, 2013.

[18] S. Li, P. Xiang, B. Wei, L. Yan, and Y. Xia, "A nonlinear static procedure for the seismic design of symmetrical irregular bridges," Shock and Vibration, vol. 2020, Article ID 8899705 , 16 pages, 2020.

[19] F. Catbas and A. E. Aktan, "A correlation function for spatial locations of scaled mode shapes-(COMEF)," in Proceedings of the 16 th International Modal Analysis Conference, Society for Experimental Mechanics, Inc, Bethel, CT, USA, January 1998.

[20] A. Pinto, G. Magonette, P. Pegon, and P. Negro, "Pseudodynamic testing of large scale RC bridges in elsa," in Proceedings of the 11th World Conference on Earthquake Engineering, CD ROOM, Acapulco, Mexico, June 1996.

[21] F. McKenna and G. Fenves, Open System for Earthquake Simulation Framework (OpenSees) Ver 2.4. 4. Pacific Earthquake Engineering Research Center (PEER), University of California, Berkeley, CA, USA, 2014.

[22] A. K. Chopra and R. K. Goel, "A modal pushover analysis procedure for estimating seismic demands for buildings," 
Earthquake Engineering \& Structural Dynamics, vol. 31, no. 3, pp. 561-582, 2002.

[23] J. B. Mander, M. J. Priestley, and R. Park, "Theoretical stressstrain model for confined concrete," Journal of Structural Engineering, vol. 114, no. 8, pp. 1804-1826, 1988.

[24] G. Chang and J. B. Mander, "Seismic Energy Based Fatigue Damage Analysis of Bridge Columns: Part 1-evaluation of Seismic Capacity," Technical Report NCEER-94-0006, NCEER, Buffalo, NY, USA, 1994.

[25] M. Mehr and A. E. Zaghi, "Contributing factors to seismic force demand on in-span shear keys in multi-frame bridges," Structure and Infrastructure Engineering, vol. 15, no. 2, pp. 206-218, 2019.

[26] K. Mackie and B. Stojadinovic, "Seismic vulnerability of typical multiple-span California highway bridges," in Proceedings of the 15th National Seismic Conference on Bridges \& Highways Multidisciplinary Center for Earthquake Engineering Research California, Department of Transportation Federal Highway Administration Transportation Research Board, San Francisco CA, USA, September 2006.

[27] S. Caltrans, Caltrans seismic design criteria, v. 1.7, Caltrans, Sacramento, CA, USA, 2013.

[28] S. Muthukumar, A Contact Element Approach with Hysteresis Damping for the Analysis and Design of Pounding in Bridges, Georgia Institute of Technology, Atlanta, Georgia, 2003.

[29] T. O. S. O. Bridges, AASHTO Guide Specifications for LRFD Seismic Bridge Design, AASHTO, Washington, DC, USA, 2011.

[30] A. Shamsabadi, K. M. Rollins, and M. Kapuskar, "Nonlinear soil-abutment-bridge structure interaction for seismic performance-based design," Journal of Geotechnical and Geoenvironmental Engineering, vol. 133, no. 6, pp. 707-720, 2007.

[31] A. Aviram, K. R. Mackie, and B. Stojadinović, "Guidelines for nonlinear analysis of bridge structures in California," Pacific Earthquake Engineering Research Center, Berkeley, CA, USA, PB2012106297, 2008.

[32] A. Kappos, G. Manolis, and I. Moschonas, "Seismic assessment and design of $\mathrm{R} / \mathrm{C}$ bridges with irregular congiguration, including SSI effects," Engineering Structures, vol. 24, no. 10, pp. 1337-1348, 2002.

[33] J. W. Baker, New Ground Motion Selection Procedures and Selected Motions for the PEER Transportation Research Program, Peer Report, Berkeley, CA, USA, 2011. 